\title{
Mirror movements of the left arm following peripheral damage to the preferred right arm
}

\author{
G D SCHOTT
}

From the National Hospital for Nervous Diseases, Queen Square, London

SUMMARY Cerebral damage which renders the preferred arm useless may lead patients to use their non-preferred arm for everyday tasks including writing. In these circumstances, mirror writing and other mirror movements may occur. The present study on 10 formerly right-handed patients was carried out to determine whether similar phenomena occurred when serious damage to the right arm itself had occurred, cerebral function remaining intact or any damage being coincidental and non-focal. The patients were asked to describe the events that had occurred when they started using their left hand, to carry out a number of writing tests, and to undertake two graphic tasks to assess directional motor preferences. Seven patients had executed mirror reversal of letters, and eight had experienced mirror phenomena when carrying out everyday tasks with their left hand; brief case histories are cited. No patient exhibited mirror writing on formal testing, and there was no evidence of alteration in the expected preference of direction in which graphic tasks were undertaken. The practical and theoretical implications of these observations are discussed.

When a stroke or other cerebral lesion prevents the preferred arm from carrying out everyday tasks, patients become obliged to use their unaccustomed arm for these tasks. If language functions remain intact, writing is an important activity which has to be relearnt, and mirror movements and especially mirror writing are well recognised occurrences in these circumstances. ${ }^{1-4}$ A number of people, however, change handedness as a consequence not of brain damage but of severe injury to their preferred arm. It is remarkable that almost no attention has been paid to the events that follow when these patients use their unaccustomed arm, and references to the production of mirror writing are sparse, implying that this is a most uncommon event. ${ }^{3} 4$

The purpose of the present study was to establish what events had occurred when the nonpreferred arm was used following serious damage to the preferred arm, to observe whether mirror movements or other reversals while writing could be demonstrated, and to assess using simple graphic tests whether there had been obvious

Address for reprint requests: Dr GD Schott, National Hospital for Nervous Diseases, Queen Square, London WCIN 3BG.

Accepted 16 April 1980 alteration in the expected direction in which motor tasks were carried out-since there is evidence of a preference for such tasks to be performed in a centrifugal direction. Thus using the preferred hand, right handers usually draw the rungs of a ladder in a left-to-right direction, whilst left handers insert them in the opposite direction. ${ }^{5}$ In a more representational test, right handers tend to draw the silhouette of a head facing towards the right, left handers drawing an equal number facing in the two directions. ${ }^{6}$

\section{Patients and methods}

Ten unselected right handed patients were studied, all of whom had used their right hand for writing before the accident. They were all patients whose right arm had become permanently damaged and functionally useless, and who had subsequently used their unaccustomed left arm for many motor tasks. They were asked without prompting to describe the events that had taken place when they began to use their left arm for everyday tasks, particularly writing. The manner and direction in which movements were carried out were assessed by observing: writing a short paragraph of their own choice; writing to dictation; writing numbers and letters at speed with eyes opened and closed; and drawing in the rungs of a ladder and the outline of a head in profile, performing these latter two tasks three times on separate occasions. 


\section{Results}

Details of the patients are summarised in the table. Seven of the 10 patients reported at some stage reversing letters but neither words nor sentences, and these and a further additional patient also described problems related to mirror phenomena in other tasks. A brief account of these sometimes remarkable features is given in the case histories below. One patient (case 2) commented on a transient phase of attempting to write with the left hand hooked over the writing line, a point considered further in the Discussion. In no patient could reversals be demonstrated on asking the patient to write in any of the situations described above. The results of the more specific directional tests are also shown in the table, from which it can be seen that there was a preference for lines to be drawn in a centrifugal direction, and variability in the preferred direction of drawing silhouettes. In three patients additional head injury had occurred, but in no case had focal cerebral damage or disturbance of language function ensued, and it is evident that the presence of a concomitant head injury did not appear to affect the occurrence of mirroring phenomena.

\section{Case histories}

$1 \mathrm{DD}$ aged 33 years. Two years ago, this building contractor fell through a window, severing the right brachial artery and median and ulnar nerves, with resultant permanent loss of useful function in the right arm. A week after the accident, he began to write using capital letters. After a few days he began to use lower case letters and ordinary script. After an interval of a few more days, he found he tended at times to mirror when writing the letters $\mathrm{c}$, $\mathrm{s}$ and the number 3 and also a tick mark. He still makes these errors five or six times per day, particularly when hurrying or not concentrating. He rotates his paper $45^{\circ}$ clockwise, and also exerts undue pressure on his pen. He has had a marked tendency to turn a screwdriver, door handle and lids of jars the opposite way to that intended, but these problems are diminishing. Playing tennis, he has noticed he of ten turns his body in the wrong direction, as if he were still playing using the right hand.

$2 \mathrm{KP}$ aged 20 years. A year ago this cost accountant was involved in a motor accident, sustaining a severe right brachial plexus injury, fractures of the right leg necessitating its amputation and a head injury with post-traumatic amnesia of a week's duration. She eventually returned to her former work. She described considerable difficulty in use of the left arm. Her script had been childish, taking some months to achieve fluency, and she had mirrored certain letters--s, b, d-for two weeks, particularly when her concentration was impaired. She never made errors with numbers which she associated with her work and took considerable care over. She had experimented with her left hand holding the pen "hooked" over the writing line, but found this difficult and unhelpful; unprompted she had tried writing from right to left for two days and, whilst obtaining no benefit from this exercise she felt "it was natural to mirror write and write right to left." She rotated her writing paper clockwise, turning her body to the right to read what she had written. In non-language functions, she had little difficulty, though had a transient tendency to comb her hair in the wrong direction, and using a mirror she found confusing.

3 ML. This 20 year old principal percussionist in the Hussars left school at the age of 15 , having taken no examinations and was barely literate. Nine months previously he sustained a complete right brachial plexus injury in a road traffic accident. Although he still wrote a little, his signature was different from that performed with the right hand, and his main problems were with joining the letters together.

Table Summary of clinical features

\begin{tabular}{|c|c|c|c|c|c|c|c|c|}
\hline Case & $\begin{array}{l}\text { Age } \\
\text { (yr) }\end{array}$ & $\operatorname{Sex}$ & Peripheral injury & $\begin{array}{l}\text { Head injury } \\
(P T A)\end{array}$ & $\begin{array}{l}\text { Mirror } \\
\text { writing* }\end{array}$ & $\begin{array}{l}\text { Other reversal } \\
\text { phenomena* }\end{array}$ & $\begin{array}{l}\text { Horizontal } \\
\text { lines } \dagger\end{array}$ & $\begin{array}{l}\text { Direction } \\
\text { of profi et }\end{array}$ \\
\hline 1 & 33 & $\mathbf{M}$ & Traumatic nerve and vessel lesions & - & + & + & $\mathbf{R}$ to $\mathbf{L}$ & $\mathbf{L}$ \\
\hline 2 & 20 & $\mathbf{F}$ & Brachial plexus injury (traumatic) & + (1 week $)$ & + & + & $\begin{array}{l}\mathbf{R} \text { to } \mathbf{L} \\
\mathbf{L} \text { to } \mathbf{R}\end{array}$ & $\overline{\mathbf{R}}$ \\
\hline 3 & 20 & $\mathbf{M}$ & Brachial plexus lesion (traumatic) & - & - & - & $\mathbf{R}$ to $\mathbf{L}$ & $\mathbf{R}$ \\
\hline 4 & 39 & $\mathbf{F}$ & Brachial plexus damage (vascular) & - & + & + & $\mathbf{R}$ to $\mathbf{L}$ & $\mathbf{L}$ \\
\hline 5 & 20 & $\mathbf{M}$ & Brachial plexus injury (traumatic) & $+(1$ month $)$ & + & + & $\mathbf{L}$ to $\mathbf{R}$ & $\mathbf{R}$ \\
\hline 6 & 20 & $\mathbf{F}$ & Progressive C5-T1 root lesions ? cause & - & + & + & $\mathbf{R}$ to $\mathbf{L}$ & $\mathbf{L}$ \\
\hline 7 & 64 & $\mathbf{M}$ & Brachial plexus injury (traumatic) & - & - & - & $\begin{array}{l}R \text { to } L \\
L \text { to } R\end{array}$ & $\mathbf{L}$ \\
\hline 8 & 19 & $\mathbf{M}$ & Brachial plexus lesion (traumatic) & - & + & + & $\mathbf{R}$ to $\mathbf{L}$ & $\mathbf{R}$ \\
\hline 9 & 40 & $\mathbf{F}$ & Volkmann's contracture of forearm & - & + & + & $\mathbf{R}$ to $\mathbf{L}$ & $\mathbf{R}$ \\
\hline 10 & 19 & $\mathbf{M}$ & Brachial plexus lesion (traumatic) & + (1 day) & - & + & $\mathbf{R}$ to $\mathbf{L}$ & $\mathbf{R}$ \\
\hline
\end{tabular}

* Mirroring and other reversal phenomena described by the patient, see Case histories

+ Direction of insertion of rungs of a ladder, see Methods

$¥$ Direction in which profile drawn, see Methods

PTA = post-traumatic amnesia 
He rotated his paper clockwise but never performed mirror writing. His motivation was not in doubt, and the had tackled six percussion instruments again with his remaining left arm.

4 DF. This 39 year old haberdasher's assistant sustained a vascular accident affecting the right brachial plexus during an orthopaedic procedure on the shoulder joint 18 months previously. She started to use the left hand six months later, commencing with small lower case script. She surprised herself by of ten executing a number of mirror letters $s, d, b$ and $p$ and numbers 6, 9 and 5-the latter sometimes appearing as 3 particularly when she was tired. These errors disappeared in a few days, but she still writes carefully and with some difficulty, and holds her pen very tightly compared with the grip she used with her right hand. Her paper is also rotated clockwise. Tasks she has found peculiarly difficult include a tendency to use a screwdriver and wind a watch in the wrong direction.

5 PB. This infantry man aged 20 years sustained a severe road traffic accident a year ago, with multiple fractures and a severe brachial plexus injury to the right arm, together with a head injury resulting in post traumatic amnesia of a month's duration. For a number of weeks he used to mirror the letters p.b,s,d and $z$ and turned rounded door handles and knobs in the reverse direction to that intended. $\mathrm{He}$ also tended to comb his hair in the wrong direction. These features disappeared after a few months.

$6 \mathrm{KK}$. This 20 year old hairdresser developed a progressive, right-sided disorder of the nerve roots in the cervico-thoracic region of undetermined cause, which resulted in an unstable scapular, recurrent dislocations of the shoulder joint, and a functionally useless right arm. For a year, she had almost exclusively used her left arm. At times she used the right hand to guide the left, initially printing letters then using small script. She had frequently mirrored the letters $\mathrm{p}, \mathrm{b}$ and $\mathrm{d}$ and rotated her paper clockwise.

Particularly striking were the variety of tasks in which difficulty had resulted from using the left arm. Apart from turning screwdrivers, bottle tops, radio knobs and door knobs in the opposite direction to that intended, she had combed her hair in the wrong direction and placed her hair parting on the wrong side, despite being a professional hairdresser. She frequently used her fork for cutting, and held her young baby to her on the unaccustomed side. The cooking pots were placed on the wrong side of the hobs so the handles had often been burnt, and for the first time she turned the pages of magazines starting from the back pages to the front. Gradually these striking problems improved but at times this type of task remained confusing.

7 JW. This 64 year old journalist fell from a bus three years ago, sustaining a complete brachial plexus injury. He had been able to return to his former full-time professional activities, and surprisingly experienced little or no problem on using his left hand for writing. He started writing within three weeks of the accident using cursive script, never reversed letters nor encountered orientation or directional problems. Moreover he did not tilt his paper and retained the conventional posture of the pen. It was clear that he was a very slow and cautious writer; he had been taught copper plate writing at school and was aware he always wrote sufficiently carefully to obviate errors and overcome problems of orientation. He had written little by hand for many years, as the large amount of writing necessary was carried out using a typewriter.

$8 \mathrm{SH}$. This 19 year old trainee technical officer sustained a right brachial plexus injury in a traffic accident two years ago. A week after the accident he began to write with his left hand. He experienced considerable difficulties: initially he had poor control of the pen, and his writing was jerky. He frequently mirrored letters, especially when he was tired and not concentrating, or when writing at speed. The affected letters were c,d,b,z and occasionally $s$ and the number 7 ; he tilted his paper $45^{\circ}$ clockwise, used excessive pressure on the pen and his hands sweated excessively when writing. He noticed at the beginning that he wanted to write from right to left, and his hand tended to go in this direction; there was a sensation of this hand drifting to the left, and this was most noticeable when he was writing quicklysomething he had always tended to do. He had occasionally turned door handles in the wrong direction, but this was the only other abnormal movement he could recall. All these difficulties subsided after a few months.

$9 \mathrm{JH}$. This 40 year old housewife fell off a fence at the age of 7 years, sustaining complex fractures in the region of the right elbow followed by Volkmann's ischaemic contractures of the forearm muscles, and eventually function of the clawed right hand became limited to rather ineffectual gripping. She recalls her writing had been good when learning to write as a child but since the accident, over 30 years ago, she has written with the left hand. Initially for some months her left handed writing had varied in its form-being sometimes upright and sometimes forward sloping. There was a phase at school of mirror writing which persisted intermittently for 10 years, but never affected numerals. She still mirrors tick marks. Her signature took 15 years to "stabilise" to a consistent style and these early years were complicated by her problems being attributed by her teachers to emotional factors. She had several problems in performing everyday tasks: difficulty in orientation turning door handles, using a screwdriver, doing up her children's coat buttons, and a tendency to place cooking pans on the left side of the stove She still frequently starts turning magazine pages from the back, something she does not recall doing earlier, and easily confuses the direction in which 
she hems whilst sewing, with a tendency to do this in the right-to-left direction. She tends to pour liquids to the left of her, holding a kettle in the left hand, that is, in an unexpected direction away from the body.

10 DK. This 19 year old panel beater sustained a severe motor-cycle injury three years ago in which he sustained a complete brachial plexus lesion and a head injury with one day's post-traumatic amnesia. He tried holding his pen in the left hand after some weeks and within an hour had managed to achieve a proper grip. He experienced no problems in writing other than a tendency to write from right-to-left for a few days. There was neither mirror writing nor problems with orientation in everyday tasks.

\section{Discussion}

From the accounts that many of these patients gave of their experience on changing handedness, two main and unexpected points emerged: first, the subjects passed through an initial phase in which they executed certain letters (but neither words nor sentences) in mirror fashion; second, they showed a tendency to undertake tasks which were directional-linear or circular-in the opposite way to that in which they were performed with the right hand. These surprisingly common manifestations varied considerably in their degree and were sometimes not seen at all, but when they did occur, they appeared stereotyped and predictable. Although the reports are anecdotal, the similarity of the various accounts is striking. There are theoretical and practical implications for these phenomena which will be considered below.

Mirror phenomena and particularly writing are well recognised as occurring in the presence of central nervous system damage, and are especially seen in association with hemiplegia. ${ }^{12}$ The patients described above, however, clearly indicate that the same phenomena occur in patients with normal brains in whom therefore normal physiological processes must be implicated, and the phenomena cannot be a sequel to cerebral damage. Mirror writing and other reversed movements are indeed normal functions, since they occur in healthy children during maturation $^{7}$ and may occasionally persist in adults who are left handed-celebrated examples including Lewis Carroll and that most famous mirror writer, Leonardo da Vinci. ${ }^{8}$ It is also pertinent that mirror phenomena have been described in the complete absence of a limb: in the amputee, movement of the normal contralateral limb may result in the subjective experience of movement in the phantom limb, especially with the execution of bilateral symmetrical associated movements. ${ }^{9}$

It should be emphasised that whilst many people can voluntarily execute mirror writing more or less easily with the non-preferred, usually left hand, this facility is different from the features seen in the patients described here. These patients were always attempting to write conventionally, and the mirror writing occurred as an unwanted and unintended intrusion. The problems in orientation seen in activities of everyday life, such as turning door handles in the wrong direction, were a considerable nuisance when they occurred and sometimes even took the patients by surprise. Mirror reversals in writing sometimes occurred "by accident"-when the writer was tired, pre-occupied, or inattentive; they were seen during the early stages of taking up writing again whenever that took place and usually resolved fairly rapidly; so too did the problems associated with other movements, though these appeared to perist longer.

What is the explanation for these observations? Some tentative hypotheses can be put forward, which inevitably become linked to a more general consideration of mechanisms of mirror movements (for discussion, see references 8,10 , 11). These movements regularly occur in infancy, particularly affect the arms and hands, tend to disappear during the first decades of life. but occasionally become manifest again in adult life during extreme physical effort; by various techniques they can be demonstrated as subclinical phenomena during normal unilateral activity. Very rarely mirror movements occur to a striking extent in otherwise normal adults, having been observed both in sporadic and familial cases. The mechanism of mirror movements is unknown, as is the way in which the mirror movements of children disappear during maturation. It should be recalled, however, that there is a long history of the concept of physiological inhibition of bimanual synkinetic movements; this concept was advanced by Westphal, ${ }^{12}$ who suggested the presence of a cerebral inhibitory mechanism, a suggestion developed by von Fragstein ${ }^{13}$ and subsequent authors (for example, Crawford ${ }^{14}$ ). This inhibitory mechanism has been considered to develop with maturation, to be deficient in "idiots," and to be damaged in the presence of certain central nervous system disorders. The present cases provide some additional support for the concept of inhibition.

In the specific instance of mirror writing, many would agree with the views first proposed by Vogt ${ }^{15}$ that this is the natural script of the left 
hander (see also references 3,8 ). During normal acquisition of conventional writing with the right hand, the left hand can be envisaged as "subclinically" performing the same activity; by use of homologous muscles or movements, this will necessarily result in "mirror" script which is of course normally suppressed. When, however, as with the present patients, the left hand is called upon to write, whilst meaningful conventional left-to-right script is usually executed, at times the suppressed mirror writing will intrude, especially for letters such as b and d, the spatially reversible letters that particularly tend to cause confusion in childhood. ${ }^{16}$ It might be anticipated that mirror writing could occur when attention was diminished and the suppressed mirror reversals with the left hand would then intrude more easily. As mentioned above, some patients reported this occurrence, and reversals sometimes appeared when the patient was tired, preoccupied or diverted. Conversely it would not occur when writing was undertaken slowly, with care and deliberation, or when writing had previously been infrequent and laboured. Moreover when the patients were asked to write during interview, mirror writing was never seen, presumably as in these circumstances writing occasioned full concentration and attention to detail. It would be predicted that in time mirror reversals would diminish as practice and superimposition of conventional script occurred, and indeed mirror writing was nearly always a transient phenomenon.

Not only mirror writing but also other mirror movements were seen, including a tendency to write in a right-to-left direction with the left hand. This has particular importance when considering mechanisms for these phenomena, because it may imply that mirror writing is $?$ phenomenon linked not to language but to movement. ${ }^{17}$ that is, in this context mirror writing is a non-linguistic function. Indeed in a right handed person whose language functions are subserved by the left hemisphere, if writing as a language skill were executed from a purely cortical and linguistic level, mirroring would not occur as both hands would be "instructed" to perform writing in the same learned and conventional direction and form. On the other hand, that mirror reversals do not always appear when the left hand writes is because conventional writing usually supersedes this tendency, only occasionally being in abeyance when mirror writing transiently emerges. It would seem therefore reasonable to propose that all movements, including those such as writing which are linguistically related, may be executed as bilateral and homologous movements-with the unwanted side being inhibited or suppressed, as Westphal12 first proposed over a century ago.

From the results of the two simple graphic tests of directional preference, it is evident that these acquired left handers showed similar preferences to those who normally exhibit a left handed preference. It provides some confirmation that mirror phenomena as shown by left handers merely reflect the "general preference to make movements in an outward direction", 5 and there is no evidence of alteration in the influence of the cerebral hemispheres on the movement of the left hand. The observation of the one patient who reported a fleeting period of writing with the hand "hooked" over the line of writing is, however, of interest. Although controversial, ${ }^{18}$ according to the theory proposed by Levy and Reid, ${ }^{19}$ this might imply that at least for motor functions there was transient use of the hemisphere ipsilateral to the non-preferred hand, before motor control from the contralateral hemisphere superseded.

Some practical aspects deserve comment. Perhaps surprisingly none of these patients received any instruction when first learning to write with their non-preferred hand; indeed neither medical nor para-medical staff had even commented on these phenomena before. Assessment of the devastating physical and psychological problems associated with these conditions and the necessary rehabilitation properly took precedence over these relatively minor aspects. It is, however, important that patients should be reassured that these apparently curious manifestations are common, and-contrary to the views expressed to one patient-have no basis in psychiatry. All patients gradually learnt to overcome their disabilities to a varying extent and in none did it represent a serious functional problem. Apart from the obvious practical difficulties of managing with only one useful hand, many patients managed remarkably well through their own initiative and effort. It is also unclear what practical advice could usefully be given, although patients had found that attention when carrying out everyday tasks seemed to obviate many of their problems. There is a limited range of everyday appliances adapted for use by the left handed, ${ }^{20}$ but it is uncertain whether specific methods of training the non-preferred hand ${ }^{21}$ and manuals for left handed writing 22 are helpfu!. None of the patients had even heard of these aids.

The small number of patients and their neces- 
sarily anecdotal and retrospective accounts do not allow general statements to be made concerning aspects such as the effect of any associated cerebral damage, the relationship to handedness and cerebral dominance, the long-term prognosis, and the frequency with which these phenomena occur-although they are liable to have been forgotten and hence under-reported. Nevertheless the histories provided by these seriously afflicted patients provide an insight into some theoretical and practical problems associated with forced change in handedness.

I am grateful to Dr CB Wynn Parry, Director of Rehabilitation, Royal National Orthopaedic Hospital, for permission to include details of patients under his care. It is a pleasure to thank Dr Maria Wyke for invaluable advice and discussion throughout this study.

\section{References}

1 Paradowski M, Ginzburg G. Mirror writing and hemiplegia. Percept Mot Skills 1971; 32:617-8.

2 Woods BT, Teuber H-L. Mirror movements after childhood hemiparesis. Neurology (Minneap) 1978; 28:1152-8.

3 Critchley M. Mirror-writing. London: Kegan Paul, Trench, Trubner \& Co, 1928.

4 Corballis MC, Beale IL. The Psychology of Left ant Right. Hillsdale, New Jersey: Lawrence Erlbaum Associates, 1976: 180-1.

5 Reed GF, Smith AC. Laterality and directional preferences in a simple perceptual-motor task. $Q J$ Exp Psychol 1961; 13:122-4.

6 Crovitz HF. On direction in drawing a person. J Consult Psych 1962; 26:196.

7 Abercrombie MLJ, Lindon RL, Tyson MC. Associated movements in normal and physically handicapped children. Dev Med Child Neurol 1964; 6:573-80.
8 Schott GD. Some neurological observations on Leonardo da Vinci's handwriting. J Neurol Sci 1979; 42:321-9.

9 Sunderland S. Nerves and Nerve Injuries. Second edition. Edinburgh: Churchill Livingstone, 1978: 429.

10 Schott GD, Wyke MA. Obligatory bimanual associated movements. J Neurol Sci 1977; 33: 301-12.

11 Zülch KG, Müller N. Associated movements in man. In: Vinken PJ, Bruyn GW, eds. Handbook of Clinical Neurology. Volume I. Amsterdam: North-Holland Publishing Co, 1969: 404-26.

12 Westphal C. Ueber einige Bewegungs-Erscheinungen an gelähmten Gliedern. Arch Psychiatr Nervenkr 1875; 5:803-34.

13 von Fragstein. Ueber Synkinesien bei intaktem Nervensystem an der Hand eines selbst beobachteten Falles. Monatsschr Psychiat Neurol 1901; 10:348-58.

14 Crawford C. Report of a family showing "mirror" movements. Australas Ann Med 1960; 9:176-9.

15 Vogt MC. L'écriture considérée au point de vue physiologique. Rev Scient (Paris) 2nd Series 1880; 18:1221-32.

16 Asso D, Wyke M. Discrimination of spatially confusable letters by young children. J Exp Child Psychol 1971; 11:11-20.

17 Brain WR. Speech Disorders. Second edition. London: Butterworths, 1965: 134.

18 Peters M, Pedersen K. Incidence of left-handers with inverted writing position in a population of 5910 elementary school children. Neuropsychologia 1978; 16:743-6.

19 Levy J. Reid M. Variations in writing posture and cerebral organisation. Science 1976; 194:337-9.

20 The left-handed report. Which? London: The Consumers' Association, 1979: 585-8.

21 Mohlman DK. A preliminary study of the problems in the training of the non-preferred hand. $J$ Educ Psychol 1923; 14:215-30.

22 Gardner WH. Left-handed writing-Instruction Manual. Danville, Illinois: Interstate Special Education Series, 1958. 